\title{
Inhibin as a Possible Indicator of Follicular Development during Perinatal Period in Mares
}

\author{
Yasuo NAMBO ${ }^{1)}$, Yumiko TANAKA ${ }^{2,3)}$, Shun-ichi NAGATA ${ }^{4)}$, Fumio SATO'), \\ Telhisa HASEGAWA ${ }^{1)}$, Rie NAKAI ${ }^{2,3}$, Hironori OKI ${ }^{1)}$, Gen WATANABE ${ }^{2)}$ and \\ Kazuyoshi TAYA ${ }^{2)}$
}

\author{
1) Laboratory of Molecular and Cellular Biology, Equine Research Institute, Japan Racing \\ Association, Tochigi 320-0856, ${ }^{2)}$ Laboratory of Veterinary Physiology, Tokyo University of \\ Agriculture and Technology, Tokyo 183-8509, ${ }^{3)}$ Department of Basic Veterinary Science, \\ The United Graduate School of Veterinary Science, Gifu University, Gifu 501-1193 \\ ${ }^{4)}$ Laboratory of Racing Chemistry, Tochigi 320-0851, Japan
}

\begin{abstract}
Plasma concentrations of immunoreactive (ir-) inhibin, FSH, LH, estradiol and progesterone were measured by RIA between -6 and 12 days after parturition in 6 mares. Follicular development was also monitored in the same animals after parturition by ultrasound scanner. Plasma concentrations of ir-inhibin were relatively low before parturition, then rose significantly after parturition, in accordance with the development of $10-30 \mathrm{~mm}$ follicles in diameter during the early period of postpartum estrus. In contrast, concentrations of both estradiol and progesterone remained high before parturition, then dropped significantly 1 day after parturition. The present study demonstrated that inhibin is more likely to be secreted from maternal ovaries into maternal circulation than the feto-placental unit during the prenatal period. This suggests that inhibin could be used as a potential indicator of follicular development around parturition in mares.

Key words: Inhibin, Estradiol, Parturition, Follicular development
\end{abstract}

(J. Reprod. Dev. 48: 265-270, 2002)

$\mathbf{T}^{\mathrm{h}}$ he majority of mares begin postpartum estrus within 5 to 12 days following parturition [1]. They are generally assumed to be ovulatory in 10.5 \pm 2.4 days after parturition [2]. During the second half of gestation, however, there is no obvious follicular development over $2.0 \mathrm{~cm}$ in diameter [3]. It is speculated that prepartum mares begin rapid growth of follicles around parturition.

Inhibin, a gonadal glycoprotein hormone, is known as an important factor in the regulation of FSH secretion in mammals [4]. In mares, plasma concentrations of immunoreactive (ir-) inhibin are high during the follicular phase of the estrous cycle,

Accepted for publication: December 26, 2001

Correspondence: Y. Nambo and have an inverse relationship with those of FSH [5-8]. These studies demonstrated that inhibin is a useful indicator for ovarian function. On the other hand, during late pregnancy, high concentrations of inhibin were shown in the ewe [9], monkey [10] and human $[11,12]$ since placenta is an origin of inhibin in these mammals. Peripheral concentrations of inhibin, therefore, fell abruptly to the basal value after parturition in these mammals. In mares, ir-inhibin, which might be secreted not from placenta but from enlarged fetal gonads, was detected in maternal plasma during 200-300 days of pregnancy [13]. Concentrations of ir-inhibin seem to be relatively low throughout parturition, because the weight of fetal gonads still decreases by 
term to approximately one tenth of that in midpregnancy. Therefore a precise profile of inhibin during the perinatal period remains an open question.

The main purpose of this study is to investigate the peripheral hormone profile associated with follicular development with special reference to inhibin during parturition and the puerperium.

\section{Materials and Methods}

\section{Animals and blood sampling}

Five Thoroughbred and one Anglo-Arab mature clinically healthy pregnant mares, aged $12.5 \pm 1.35$ and weighing $500-620 \mathrm{~kg}$ were used in this study during the breeding season in 1995 . They were housed individually and allowed to graze each day at the Equine Research Institute, Epizootic Research Station, Tochigi Prefecture, Japan. They were fed balanced pelleted food and hay twice daily. The gestation period of the 6 mares was $337.4 \pm 1.1$ days and all of them delivered healthy foals spontaneously. Blood samplings from a jugular vein were performed with heparinized tubes daily between 9:00-11:00 from 7 days before the expected gestation period (335 days) to 12 days after parturition. All 6 pregnant mares gave a birth between 17:00-24:00. The day of parturition (Day 0 ) was defined by the 24-hour period from 0:00 to 24:00. Five of 6 mares ovulated at 10-12 days after parturition, whereas the other mare ovulated at 18 days after parturition. Plasma was stored at $-30 \mathrm{C}$ until assay for hormone concentrations.

\section{Hormone assay}

Concentrations of immunoreactive (ir-) inhibin in plasma and placental homogenates were determined by double antibody radioimmunoassay (RIA) as described previously [14]. The antiserum used in this study was anti-bovine inhibin serum (rAS-\#1989, kindly provided by Dr. D. M. de Kretser). This has no cross-reactivity with bovine activin $\mathrm{A}$, however it does cross-react with inhibin pro- $\alpha C$ in the RIA [15]. Iodinated ligand and reference standard were $32 \mathrm{kDa}$ bovine inhibin. The sensitivity of this assay was $7.8 \mathrm{pg} /$ tube. The intra- and inter-assay coefficients of variation were $7.4 \%$ and $10.5 \%$, respectively.

Plasma concentrations of $\mathrm{LH}$ were measured by a heterologous double-antibody RIA using an anti- ovine LH serum (YM\#18, kindly provided by Dr. Y. Mori), and highly-purified equine LH (E98A, kindly provided by Drs. J. F. Roser and H. Papkoff) for radioiodination and a reference standard [16]. Plasma concentrations of FSH were measured in a heterologous RIA using an anti-human FSH serum raised in a rabbit (M91, Endocrine Services Limited, Warwickshire, UK), and purified equine FSH (E219B, kindly provided by Drs. J. F. Roser and H. Papkoff) for radioiodination and a reference standard [16]. The intra- and inter-assay coefficients of variation were 8.8 and $13.0 \%$ for the LH assay and 6.9 and 9.7\%, for the FSH assay, respectively.

Plasma concentrations of estradiol-17 $\beta$ and progesterone were measured by double-antibody RIAs using ${ }^{125}$ I-labeled radioligands [17], after steroid extraction for both hormones using diethylether and defatting for estradiol-17 $\beta$ using hexane and acetonitrile as described previously [18]. Antisera against estradiol-17 $\beta$ (GDN 244, [19]) and progesterone (GDN 377, [20]), kindly provided by Dr. G.D. Niswender) were used in each assay. The intra- and inter-assay coefficients of variation were 4.8 and $5.8 \%$ for estradiol and 3.5 and $13.4 \%$ for progesterone, respectively.

\section{Examination of follicular development}

Ovaries were monitored by ultrasound scanner with a $5 \mathrm{MHz}$ linear transducer (SSD-330, Aloka, Tokyo, Japan) and recorded by videocassette recorder (U-matic, SONY, Tokyo, Japan) at 2 days intervals from 2 days after parturition until postpartum ovulations occurred. The diameter was defined as the mean value between width and length. The number of follicles over $10 \mathrm{~mm}$ in diameter, the diameter of the largest follicles and the day of ovulations in each mare were estimated from the paused image.

\section{Statistical analysis}

All data were normalized to the days before and after actual parturition and were expressed as mean \pm S.E.M. The results were subjected to an analysis of variance for repeated measurements to determine the effect of time on plasma concentrations of the hormones measured. The significance of the difference between periods before and after parturition was tested. When more than two means were compared, the significance of the difference between means was determined by 
Duncan's multiple range test. All the data were analyzed using the GLM procedure of the Statistical Analysis Systems [21]. A value of $\mathrm{p}<0.05$ was considered to be significant.

\section{Results}

Changes in plasma concentrations of ir-inhibin, FSH, $L H$, estradiol and progesterone around parturition (Fig. 1)

All hormone concentrations changed significantly $(\mathrm{p}<0.05)$ with respect to the day of the estrous cycle. Plasma concentrations of ir-inhibin remained low ranging from 200 to $300 \mathrm{pg} / \mathrm{ml}$ until the day of parturition, then they increased to a peak $(650 \pm 191 \mathrm{pg} / \mathrm{ml})$ at 3 days after parturition. The levels of ir-inhibin were higher $(\mathrm{p}<0.05)$ during the postpartum period than the prepartum period.

Plasma concentrations of FSH did not change throughout parturition, with a maximum levels of $19.1 \pm 8.69 \mathrm{ng} / \mathrm{ml}$ one day after parturition. On the other hand, plasma concentrations of LH gradually increased until postpartum ovulation, though they did not show any increases or decreases around the time of parturition.

Plasma concentrations of estradiol were high, with a peak of $415 \pm 53.9 \mathrm{pg} / \mathrm{ml}$ at 2 days before parturition, then dropped significantly $(\mathrm{p}<0.001) 1$ day after parturition, compared with 0 day. Plasma progesterone concentrations also reached a peak levels of $14.8 \pm 1.39 \mathrm{ng} / \mathrm{ml}$ at 2 days before parturition, and thereafter decreased $(\mathrm{p}<0.1)$ to 0.93 $\pm 0.2 \mathrm{ng} / \mathrm{ml}$ with a similar profile to estradiol.

\section{Profiles of ir-inhibin, estradiol, and follicular development}

Plasma concentrations of ir-inhibin and estradiol, follicular size and the number of follicles were shown in Fig. 2. Plasma concentrations of estradiol remained high during pregnancy, then decreased sharply to a level ranging from 20 to $40 \mathrm{pg} / \mathrm{ml}$, whereas there was no decrease in plasma concentrations of ir-inhibin at the time of parturition. The levels of ir-inhibin were relatively low before parturition, but thereafter became significantly higher than before parturition.

The mean largest follicular diameter was $18.3 \pm$ $3.3 \mathrm{~mm}$ at 2 days after parturition. It gradually increased and reached $43.0 \pm 2.1 \mathrm{~mm}$ at 10 days after parturition. In 2 of 6 mares, two follicles
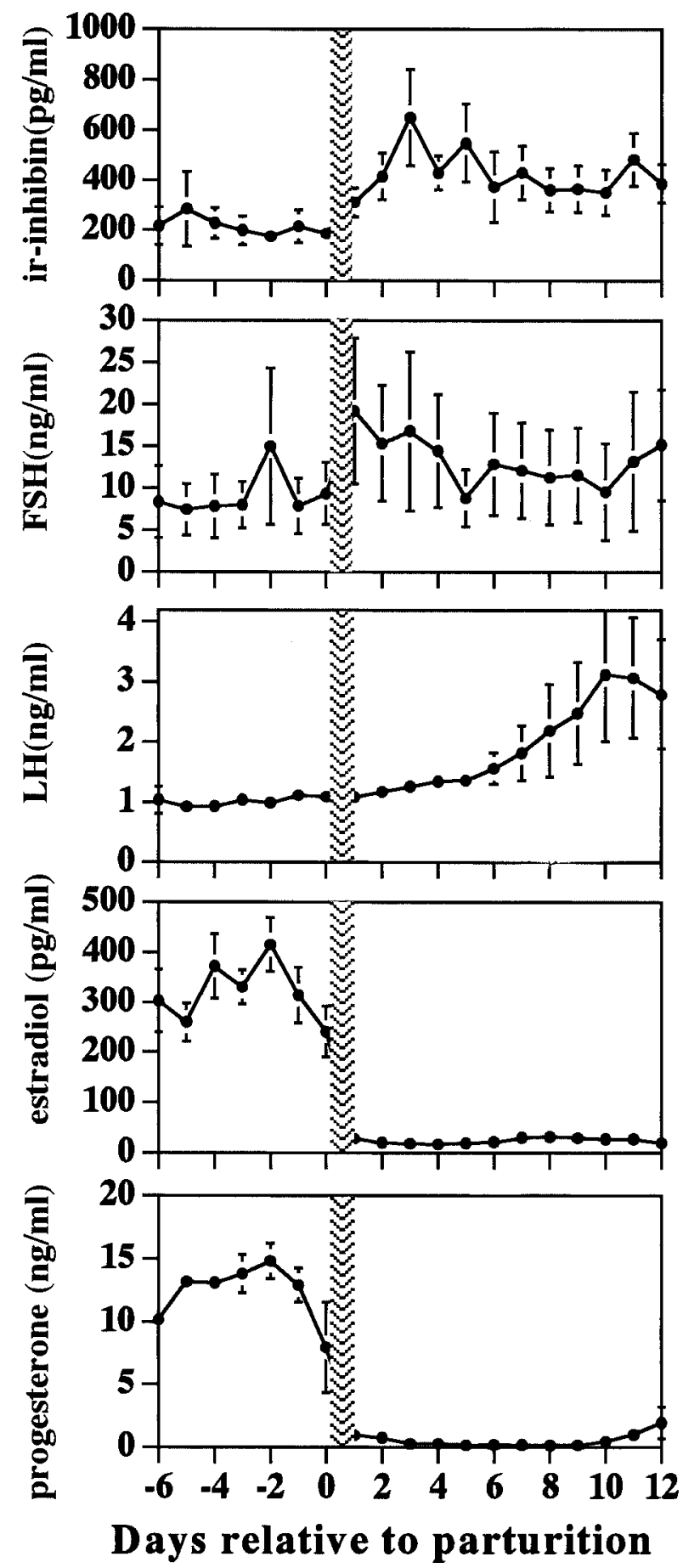

Fig. 1. Changes in plasma concentrations of ir-inhibin, FSH, $\mathrm{LH}$, estradiol and progesterone around parturition in mares. Data were expressed as mean \pm S.E.M.

developed synchronously, resulting in double ovulation. On the other hand, the number of follicles between $10-30 \mathrm{~mm}$ in diameter was a maximum, $4.3 \pm 1.08$, at 3 days after parturition and 

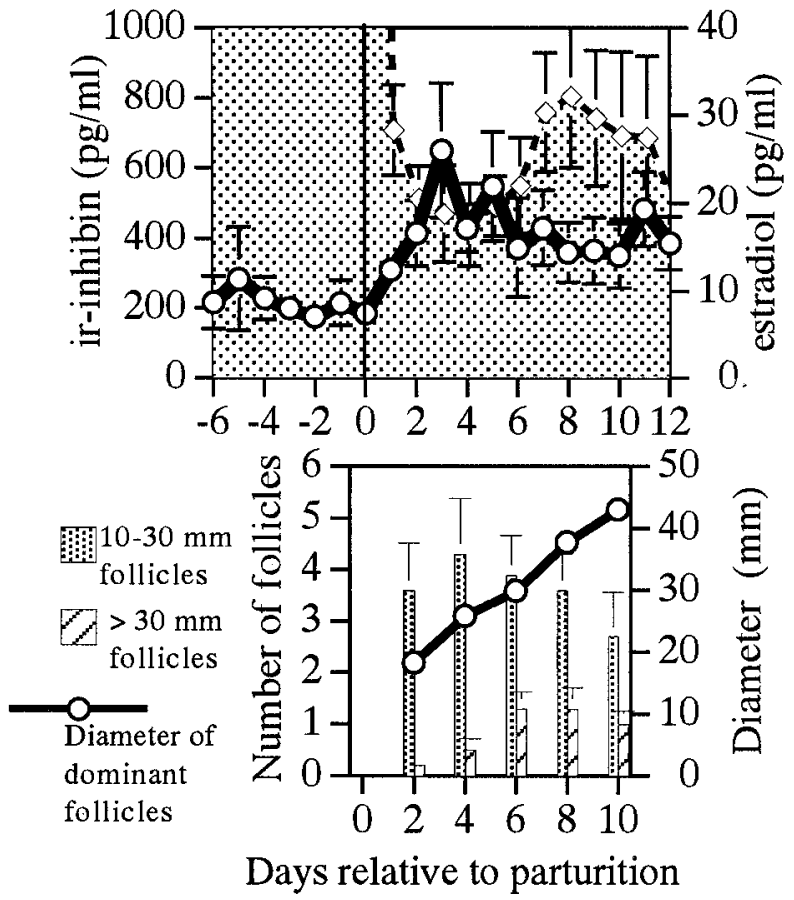

Fig. 2. Relationship among concentrations of ir-inhibin $(\bigcirc)$, estradiol ( $\diamond)$ and follicular dynamics (lower graph) around parturition in mares. Data were expressed as mean \pm S.E.M.

then gradually decreased until postpartum ovulation.

Changes in plasma concentrations of ir-inhibin were similar to the profile of the number of 10-30 $\mathrm{mm}$ follicles in diameter.

\section{Discussion}

The present study demonstrated for the first time that dynamic changes in plasma concentrations of ir-inhibin are found in accordance with follicular development after parturition. At the time of parturition, plasma concentrations of ir-inhibin did not change abruptly, suggesting that ir-inhibin is more likely to be secreted from the maternal ovaries than the feto-placental unit. Therefore the present study suggests that inhibin become a possible indicator to monitor follicular development around parturition in mares.

A marked increase in plasma concentrations of ir-inhibin has been found during the second half of pregnancy in mares [13]. The source of ir-inhibin appears not to be placenta but fetal gonads since homogenates prepared from the fetal gonads contained a large amount of ir-inhibin. In addition, expression and cellular localization of inhibin $\alpha$ subunit mRNA were found in equine fetal gonads [22], but not in placenta at all stages of gestation [23]. Equine fetal gonads enlarge to peak levels at 220-250 days of gestation $[24,25]$ and then decrease a weight by birth to approximately one tenth of that in mid-pregnancy. In humans, serum concentrations of ir-inhibin abruptly decrease at delivery because of placental secretion of inhibin $[12,26]$. In the present study, at term, circulating concentrations of steroid hormones sharply decreased within one day after parturition, due to the expulsion of placenta. On the other hand, plasma concentrations of ir-inhibin remained steady and did not show any decreases throughout parturition. These results suggest that the source of ir-inhibin detected in the maternal plasma around parturition is the maternal ovaries.

Around 40 to 60 days of gestation, multiple follicular development and luteinization/ ovulations occur to form following accessory corpora lutea [27]. In contrast to the early gestation period, no large follicles and corpora lutea are found in the ovaries during the second half of pregnancy [3]. In general, it is impossible to check ovarian function by rectum palpation during the second half of pregnancy, because of the increasing volume of the uterus caused by fetal development. However, a largest follicle of $16.9 \pm 1.2 \mathrm{~mm}$ on the day of parturition has been reported [28] and in this study, we observed a largest follicle of $18.3 \pm 3.3$ $\mathrm{mm}$ at 2 days after parturition. In addition, the profile of ir-inhibin was similar to the dynamics of small and medium sized follicular development. Furthermore, equine inhibin is secreted from not only large follicles but also from small and medium sized follicles [29]. These results seem to show that initiation of follicular development still occurs at the end of gestation before parturition. Although estradiol is a suitable indicator for follicular development during the estrous cycle, it is difficult to detect ovarian estradiol during the second half of gestation in mares, due to masking by estradiol of placental origin. Therefore, measurement of circulating concentrations of inhibin may be a useful method for detecting follicular development around parturition in mares.

Plasma concentrations of ir-inhibin are higher during the follicular phase than the luteal phase of 
the estrous cycle, with a reciprocal relationship to FSH concentrations in mares [5-8]. In addition, passive immunization of mares against inhibin resulted in a significant rise in plasma concentrations of FSH and the number of ovulations [30]. These results suggest that inhibin is an important factor in the regulation of FSH secretion during the estrous cycle in mares. In periparturient mares, a significant increase in mean FSH concentrations occurred between day -2 and 0 , followed by a significant decrease between 3 and 7 days after parturition, with a similar change to that occurring during late diestrus and estrus [28]. In the present study, however, basal levels of FSH did not change throughout parturition despite the low levels of ir-inhibin before parturition. The reason is unclear but there may be a large variance among individuals measured by daily blood sampling, which does not always reflect the pulsatility of FSH. Further studies are needed to clarify the role of inhibin in the regulation of FSH secretion during the perinatal period in mares.

In conclusion, increases in plasma levels of irinhibin associated with follicular development were found during the first week after parturition in mares. The present study also indicates that inhibin, but not estradiol is a potential marker of follicular development throughout parturition in mares.

\section{Acknowledgments}

We thank Dr. D. M. de Kretser of the Institute of Reproduction and Development, Monash University, Clayton, Victoria, Australia, Drs. J. F. Roser and H. Papkoff, Department of Animal Science, University of California, Davis, CA, U.S.A., Dr. Y. Mori, Tokyo University, Tokyo, Japan and Dr. G. D. Niswender, Animal Reproduction and Biotechnology Laboratory, Colorado State University, Fort Collins, CO, U.S.A. for providing RIA materials. We also wish to thank Dr. T. Kanemaru and the horse barn crew of Japan Racing Association, Equine Research Institute, Epizootic Research Station, for help with animal care and excellent technical assistance.

\section{References}

1. Matthews RG, Ropiha RT, Butterfield RM. The phenomenon of foal heat in mares. Aust Vet J 1967; 43: 579-582.

2. Loy RG. Characteristics of postpartum reproduction in mares. Vet Clin North Am Large Anim Pract 1980; 2: 345-349.

3. Cole HH, Howell CE, Hart GH. The changes occurring in the ovary of the mare during pregnancy. Anat Rec 1931; 49: 199-209.

4. Burger HG, Igarashi M. Inhibin: definition and nomenclature, including related substances. J Endocr 1988; 117: 159-160.

5. Bergfelt DR, Mann BG, Schwartz NB, Ginther OJ. Circulating concentrations of immunoreactive inhibin and FSH during the estrous cycle of mares. Equine Vet J 1991; 11: 319-322.

6. Roser JF, McCue PM, Hoya Y. Inhibin activity in the mare and stallion. Domest Anim Endocrinol 1994; 11: 87-100.

7. Nagamine $\mathbf{N}$, Nambo $\mathbf{Y}$, Nagata $S$, Nagaoka $K$, Tsunoda N, Taniyama H, Tanaka Y, Tohei A, Watanabe G, Taya K. Inhibin secretion in the mare: localization of inhibin $\alpha, \beta \mathrm{A}$ and $\beta \mathrm{B}$ subunits in the ovary. Biol Reprod 1998; 59: 1392-1398.

8. Nagaoka $K$, Nambo $Y$, Nagamine $N$, Nagata $Y$,
Tanaka H, Shinbo N, Tsunoda H, Taniyama G, Watanabe N, P Groome, Taya K. A selective increase in circulating inhibin and inhibin pro- $\alpha \mathrm{C}$ at the time of ovulation in the mare. Am J Physiol 1999; 277: E870- E875,

9. Findlay JK, Doughton BW, Russell DL. Peripheral concentrations of immunoreactive inhibin during pregnancy and parturition in the ewe. Reprod Fertil Dev 1991; 3: 543-549.

10. Nozaki M, Watanabe G, Taya K, Katakai Y, Wada I, Sasamoto S, Oshima K. Changes in circulating inhibin levels during the pregnancy and early lactation of the Japanese monkey. Biol Reprod 1990; 43: 444-449.

11. Kettel LM, Roseff SJ, Bangah ML, Burger HG, Yen SS. Circulating levels of inhibin in pregnant women at progesterone after delivery. Clin Endocrinol (Oxf) 1991; 34: 19-23.

12. Abe $Y$, Hasegawa $Y$, Miyamoto $K$, Yamaguchi M, Andoh A, Ibuki Y, Igarashi U. High concentrations of plasma immunoreactive inhibin during normal pregnancy in women. J Clin Endocrinol Metab 1990; 71: 133-137.

13. Nambo $Y$, Nagata S, Oikawa M, Yoshihara T, Tsunoda N, Kohsaka T, Taniyama H, Watanabe G, 
Taya K. High concentrations of immunoreactive inhibin in the plasma of mares and fetal gonads during the second half of pregnancy. Reprod Fertil Dev 1996; 8: 1137-1145.

14. Hamada T, Watanabe G, Kokubo T, Taya K, Sasamoto S, Hasegawa Y, Miyamoto K, Igarashi M. Radioimmunoassay of inhibin in various amimals. J Endocrinol 1989; 122: 697-704.

15. Robertoson DM, Giacometti M, Foulds LM, Lahnstein J, Gross NH, Hearn MTW, de Kretser DM. Isolation of inhibin $\alpha$ subunit precursor proteins from bovine follicular fluid. Endocrinology 1989; 125: 2141-2149.

16. Nagata $S$, Miyake $\mathbf{Y}$, Nambo $\mathbf{Y}$, Nagamine $N$, Watanabe G, Tsunoda N, Taniyama H, Hondo E, Yamada J, Taya K. Inhibin secretion in the stallion. Equine Vet J 1998; 30: 98-103.

17. Taya K, Watanabe G, Sasamoto S. Radioimmunoassay for progesterone, testosterone and estradiol-17 $\beta$ using ${ }^{125}$ I-iodohistamine radioligands. Jpn J Anim Reprod 1985; 31: 186-197.

18. Nagata S, Kondo M, Kaneko H, Araki K, Nambo Y, Oikawa M, Watanabe G, Taya K. A simple defatting method using a partition method of acetonitrile and n-hexane for radioimmunoassay of low blood levels of estradiol-17 $\beta$. J Reprod Dev 1996; 42: 43-49.

19. Korenman SG, Stevens RH, Carpenter LA, Robb M, Niswender GD, Sherman BM. Estradiol radioimmunoassay without chromatography: procedure, validation and normal value. I Clin Endocrinol Metab 1974; 38: 718-720.

20. Gibori G, Anrczak E, Rothchild I. The role of estrogen in regulation of luteal progesrerone secretion in the rat after day 12 of pregnancy. Endocrinology 1977; 100: 1483-1495.

21. SAS. SAS/STAT User's Guide, release 6.03. Cary, NC: Statistical Analysis System Institute, Inc., 1988.

22. Yamanouchi K, Hirasawa K, Hondo E, Hasegawa
T, Ikeda A, Sugawara Y, Matsuyama S, Miyazawa K, Sawasaki T, Tojo H, Tachi C, Takahashi M. Expression and cellular localization of inhibin alpha-subunit mRNA in equine fetal gonads. $J$ Vet Med Sci 1997; 59: 569-573.

23. Yamanouchi K, Hirasawa K, Hasegawa T, Ikeda A, Chang KT, Matsuyama S, Nishihara M, Miyazawa K, Sawasaki T, Tojo H, Tachi C, Takahashi M. Equine inhibin/activin beta A-subunit mRNA is expressed in the endometrial gland, but not in the trophoblast, during pregnancy. Mol Reprod Dev 1997; 47: 363-369.

24. Cole HH, Hart GH, Lyons WR, Catchpole HR. The development and hormonal content of fetal horse gonads. Anat Rec 1933; 56: 275-289.

25. Wesson JA, Ginther OJ. Fetal and maternal gonads and gonadotrophins in the pony. Biol Reprod 1980; 22: 735-743.

26. Petraglia F, Sawchanko P, Lin ATW, Rivier J, Vale W. Localization, secretion and action of inhibin in human placenta. Science 1987; 237: 187-189.

27. Ginther OJ. Reproductive Biology of the Mare. Maternal aspect of pregnancy. In: Basic and Applied aspect, 2nd ed. Equiservices; 1992: pp 324-328.

28. Ginther OJ, Baucus KL, Bergfelt DR. Follicular and FSH responses to parturition during the anovulatory season in mares. Theriogenology 1994; 41: 613-627.

29. Tanaka $\mathbf{Y}$, Nagamine N, Nambo $Y$, Nagata $S$, Nagaoka K, Tsunoda N, Taniyama H, Oikawa $M$, Yoshihara T, Watanabe G, Taya K. Ovarian secretion of inhibin in mares. J Reprod Fertil Suppl 2000; 56; 239-245.

30. Nambo $\mathbf{Y}$, Kaneko $\mathbf{H}$, Nagata $S$, Oikawa $\mathbf{M}$, Yoshihara T, Nagamine N, Watanabe G, Taya K. Effect of passive immunization against inhibin on FSH secretion, folliculogenesis and ovulation rate during the follicular phase of the estrous cycle in mares. Theriogenology 1998; 50: 545 -557. 